\title{
Geotecnologias para monitoramento florestal no município de Nova Palma - Rio Grande Do Sul - BR
}

\author{
GEotechnologies for forest monitoring in the city of Nova Palma - Rio Grande Do \\ Sul - BR
}
Douglas Stefanello Facco, Ana Caroline Paim Benedetti, Waterloo Pereira Filho, Eduardo André Kaiser e Janderlei Velasque Dal Osto

Universidade Federal de Santa Maria, Santa Maria, RS, Brasil

\begin{abstract}
Resumo
A ocupação do espaço pelo homem sempre esteve associada à apropriação dos recursos naturais, sendo muito necessário o conhecimento sobre a dinâmica do uso e cobertura da terra. Nesse intuito o presente trabalho investiga a dinâmica temporal das áreas de cobertura florestal, a partir de geotecnologias como o Sensoriamento Remoto. A metodologia partiu da realização do mapeamento mutitemporal da cobertura florestal do município de Nova Palma, localizado na região da Quarta Colônia de Imigração Italiana, RS. Para isso utilizou-se o software SPRING, na classificação supervisionada de imagens do satélite Landsat 5 no ano 1985 e satélite Landsat 8 no ano 2014. Posteriormente, a análise espacial por meio da Linguagem Espacial para Geoprocessamento Algébrico (LEGAL) permitiu averiguar as seguintes situações: regeneração florestal, desmatamento e manutenção. Os resultados revelam que as áreas de reflorestamento se concentram na área de influência da Usina hidrelétrica de Dona Francisca. As áreas de desmatamento ocorreram nas áreas de terras que estão sendo preparadas para algum cultivo. A manutenção se deu em áreas de maior declividade de terreno, topos de moro e entorno da rede hidrográfica consideradas Áreas de Preservação Permanente (APP). Conclui-se que o processo de expansão florestal foi predominante no município durante o período monitorado.
\end{abstract}

Palavras-chave: Sensoriamento Remoto. Dinâmica florestal. Geoprocessamento Algébrico.

\begin{abstract}
Human land occupation has always been associated to gathering natural resources, where it is necessary to know about land coverage and usage dynamics. This way, the purpose of this work is to investigate temporal dynamics of forest coverage, by geotechnologies such as Remote Sensing. Methodology starts by multitemporal mapping of forest coverage in the municipality of Nova Palma, located in the Quarta Colônia de Imigração Italiana (fourth colony of italian imigration), Rio Grande do Sul. Using software SPRING, in monitored classification of satellite images of Landsat 5 Satellite in the year of 1985 Landsat 8 Satellite in the year of 2014. Afterwards spatial analysis, by Spatial Lenguage for Algebric Geopressessing (LEGAL), it was able to determine the following situation: forestal regeneration, deforestation and maintenance. Results show that reforestation areas concentrate in the influence area of Usina Hidreletrica de Dona Francisca (Hydroeletric Plant of Dona Francisca). Areas of deforestation ocurred in areas that the land are being prepared to production. The maintenance was by areas of greater terrain declivity, hill tops and watershed surroundings, areas considered Areas of Permanent Preservation (Área de Presevação Permanente - APP). In conclusion, the forestal expansion process was predominant in the municipality during monitoration season.
\end{abstract}

Keywords: Remote Sensing, Florest dynamics, Algebraic Geoprocessing. 
Facco et al.: Geotecnologias para monitoramento florestal no município de Nova Palma...

\section{Introdução}

Com o passar dos anos o ser humano vem modificando o ambiente de acordo com seus interesses, criando novos cenários e alterando o meio no qual vive. A ocupação do espaço pelo homem está associada à apropriação dos recursos naturais o que tem gerado nas últimas décadas o aumento no interesse acerca de questões ambientais, como a preservação do meio ambiente, bem como sua manutenção e recuperação. Neste contexto é necessário identificar e compreender as formas do espaço para ter conhecimento dos usos e ocupação da terra em determinada área e em diferentes períodos.

O sensoriamento remoto vem contribuir de maneira significativa no processo e identificação do uso e cobertura da terra, pois possibilita a obtenção de informações da superfície terrestre de maneira remota. Novo (2008), conceitua sensoriamento remoto como a utilização conjunta de sensores, equipamentos para processamento e de transmissão de dados postos a bordo de aeronaves, espaçonaves, ou outras plataformas, com o objetivo de estudar eventos, fenômenos e processos que ocorrem na superfície do planeta Terra através do registro e da análise das interações entre a radiação eletromagnética e as substâncias que o compõem a em suas mais diversas manifestações.

A utilização de imagens orbitais obtidas por sensoriamento remoto no mapeamento do uso e cobertura da terra possibilita a geração de informações rápidas, confiáveis e atualizadas sobre dado ambiente, bem como a possibilidade de acompanhamento sazonal de dada porção da superfície terrestre. Segundo Silva et al. (2013), o mapeamento do uso da terra mediante técnicas de análises espaciais são o meio mais rápido e fácil para análise dos fenômenos naturais nas mais variadas escalas.

Conforme Câmara, Davis e Monteiro (2001) o Geoprocessamento e os Sistemas de Informação Georreferenciadas (SIG) são ferramentas computacionais que possibilitam a integração de dados de diversas fontes e a realização de analises complexas. Os Sistemas de Informação Geográfica (SIG) em sua maioria oferecem operações de álgebra de mapas através de linguagens de comandos. Essas linguagens permitem ordenar sequências de transformações dos dados com objetivo de gerar novos mapas a partir dos mapas existentes (LUCENA et al., 1999).

Para que se possam perceber mudanças ocorridas em determinado ambiente se fazem necessário a utilização de imagens de satélites oriundas de diferentes datas, obtendo-se assim uma análise multitemporal. Os trabalhos que abordam a análise multitemporal com imagens de satélite, cada vez mais se intensificam, servindo para o monitoramento do crescimento urbano bem como a evolução do desmatamento e extensão agrícola entre outros (CARVALHO JÚNIOR et al., 2005).

A utilização de uma série temporal de imagens permite a confecção de diversos mapas de uso da terra o que possibilita comparações entre os mesmos a quantificação das alterações ocorridas nessas porções do ambiente permitindo o monitoramento de áreas florestais quanto às suas taxas de manutenção, redução ou expansão. E nesse intuito, o presente trabalho visa realizar uma análise multitemporal da cobertura florestal do presente município de Nova Palma, RS, nos anos de 1985 e 2014, por meio de mapeamentos temáticos e de análise espacial em Linguagem Espacial para Geoprocessamento Algébrico (LEGAL).

\section{Materiais e Métodos}

A metodologia usada neste trabalho foi realizada sequencialmente nas etapas a seguir: revisão teórica, download e importação de imagens orbitais, processamento digital das imagens com georreferenciamento, realce por contraste, classificação digital do uso da terra, validação das classificações, Análise em Linguagem Espacial para Geoprocessamento Algébrico (LEGAL) e layout dos mapas.

\section{1 Área de estudo}

Nova Palma localiza-se entre as coordenadas geográficas de $53^{\circ} 13^{\prime} 45^{\prime \prime}$ e $53^{\circ} 31^{\prime} 32^{\prime \prime}$ de longitude Oeste e $29^{\circ} 32^{\prime} 15^{\prime \prime}$ e $29^{\circ} 20^{\prime} 19^{\prime \prime}$ de latitude Sul (Fig. 1). Em 2010 a população do município era de 6.342

REGET - V. 20, n. 1, jan.- abr. 2016, p.417-426 
Facco et al.: Geotecnologias para monitoramento florestal no município de Nova Palma...

habitantes (IBGE 2015). A economia está baseada na prestação de serviços, indústria e agropecuária respectivamente. Localiza-se geomorfologicamente na transição entre a Depressão Periférica SulRiograndense e o Planalto da Bacia do Paraná, área definida como Rebordo do Planalto da Bacia do Paraná, com altitudes que podem ser inferiores a 80m e picos com mais de 500m (ROSSATO, 2010).

O município é banhado por dois rios, o Rio Soturno e o Rio Jacuí, os dois pertencem a bacia do Guaíba. O rio Jacuí se destaca pelo seu grande potencial hidrelétrico, possuindo várias usinas, dentre elas a Usina de Dona Francisca (quinta usina desse rio) com capacidade para produzir energia suficiente para abastecer uma cidade de 350 mil habitantes, está situada no município de Nova Palma (FERRARI, 2008).

Quanto à formação vegetal, Nova Palma possui restinga, campos com capões e mata nativa em grande extensão, que faz parte do ecossistema da Mata Atlântica. Essa mata expressa grande diversidade de espécies como cedro, canjerana, louro, figueira, camboatá, mamica de cadela (FERRARI, 2008).

O clima da cidade de Nova Palma é caracterizado pela ocorrência de chuvas todos os meses do ano, em torno de 1750 milímetros anuais, por possuir a temperatura do mês mais quente superior a $22^{\circ}$ e a do mês mais frio superior a - 3 C.; de acordo com a classificação de Koppen, o clima é do tipo Cfa, (clima temperado úmido com verão quente) (MORENO ,1961).
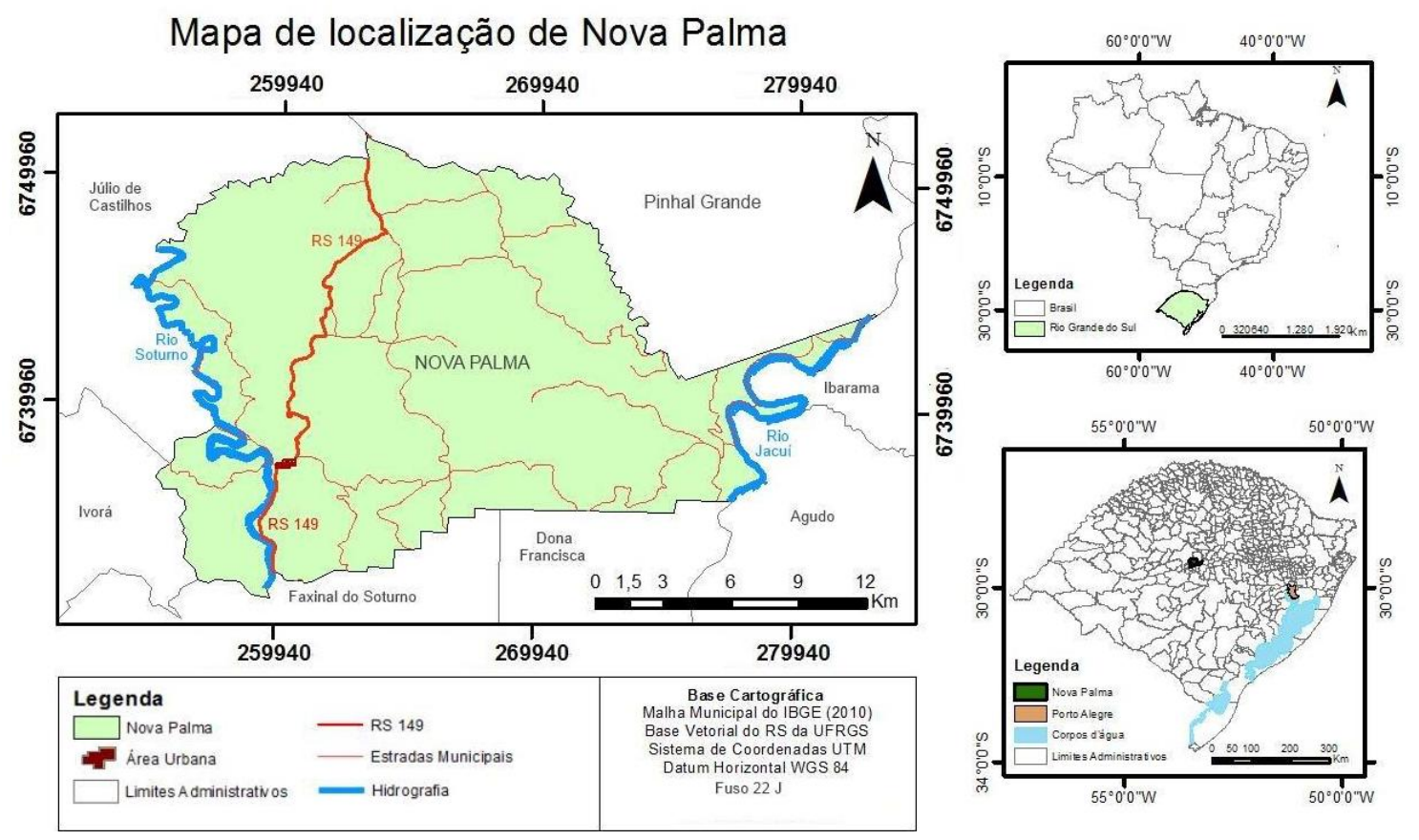

Figura 1 - Mapa de localização do município de Nova Palma/RS

\subsection{Download e importação de imagens orbitais}

Para análise e mapeamento das classes de uso e cobertura da terra, optou-se pelas imagens dos satélites Landsat 5 e Landsat 8. A escolha justifica-se pela disponibilidade gratuita e pela resolução temporal de 16 dias, que permite boa disponibilidade de imagens, e pela resolução espacial de 30 metros, adequada para o estudo de recursos terrestres em âmbito municipal.

$\mathrm{O}$ download dos arquivos de imagens foi através do site do Instituto Nacional de Pesquisas Espaciais (INPE) e National Aeronautics and Space Administration (NASA).

Para o mapeamento histórico do município, foi analisada inicialmente a imagem Landsat Thematic Mapper (TM) de 23 de julho de 1985, ano que constitui os primeiros registros de dados disponíveis, e a imagem Landsat Operational Land Imager (OLI) de 24 de agosto de 2014. A órbita-ponto é 222-080, e as bandas espectrais processadas foram: 1 (azul), 2 (verde), 3 (vermelho), ambas do espectro visível, 4 (do 
Facco et al.: Geotecnologias para monitoramento florestal no município de Nova Palma...

infravermelho próximo) e 5 (do infravermelho médio) do sensor TM e bandas 2 (azul), 3 (verde), 4 (vermelho visível), 5 (infravermelho próximo) e 6 (infravermelho médio) do sensor OLI.

As imagens, originalmente disponíveis em formato GeoTiff, foram convertidas e importadas no aplicativo SPRING, sendo posteriormente submetidas à diferentes técnicas de processamento digital.

\subsection{Processamento das imagens}

Processamento digital de imagens para Meneses e Almeida (2012) consiste na mais aconselhável realização de operações matemáticas de dados, visando as suas transformações em imagens de melhores qualidades espectrais e espaciais e que sejam mais apropriadas para uma determinada aplicação. Os mesmos autores destacam que o processamento de imagens é configurado por algoritmos especializados, que disponibiliza para o usuário a aplicação de uma grande variedade de técnicas de processamento. Seu objetivo, conforme Florenzano (2011) é melhorar o aspecto visual de certas feições estruturais para o interprete e fornecer outros subsídios para sua interpretação, gerando produtos que posteriormente sejam submetidos a outros processamentos. Pelas técnicas de processamento digital de imagens reparam-se as imagens, com o objetivo de corrigir distorções ou extrair informações.

Técnicas como georreferenciamento, realce por contraste linear e classificação digital, foram usadas para interpretação, extração de informações e comparação entre as imagens da série temporal.

Após a importação, as imagens passaram pelo processo de realce por contraste. As cenas do ano de 1985, obtidas pelo sensor TM, foram usadas para elaborar as seguintes composições de imagens utilizando os canais do visível para associação visual das bandas na sequência a seguir: RGB 321 (composição em colorida em cores naturais), RGB 432 (composição colorida falsa-cor na qual as florestas aparecem em vermelho escuro) e RGB 543 (composição colorida falsa-cor na qual as florestas aparecem em verde claro). A imagem do ano de 2014, do sensor OLI, foi usada para elaborar as composições RGB 432, RGB 543 e RGB 654, as quais equivalem respectivamente ao mesmo resultado visual descrito para o sensor TM. Sobre as composições de imagens elaboradas, foi aplicada a técnica de contraste linear, usada para realce e melhor observação das feições de interesse (Novo, 2008; Jensen, 2009), além de melhor diferenciação nos padrões de uso e cobertura da terra, dentre os quais foi possível identificar as seguintes classes: campo, floresta, solo exposto, agricultura, água e ainda sombra, que estavam presentes nas imagens analisadas.

Depois de realçadas as imagens passaram pelo procedimento de georreferenciamento este processo é descrito por Teixeira e Christofoletti (1997) como sendo a situação em que uma entidade geográfica é referenciada espacialmente ao terreno por meio de sua localização, utilizando-se para tal um sistema de coordenadas conhecido no qual a localização de um ponto da superfície da Terra pode ser identificada. O georreferenciamento de imagens foi importante pois as cenas de diferentes datas por não apresentarem coincidência com relação à sua referência geográfica quando sobrepostas. Dessa forma, buscou-se pontos de fácil identificação visual na imagem mais recente do ano de 2014, como barragens, cruzamentos de estradas, etc. para a tomada de coordenadas e a cena do ano de 1985 foi georreferenciadas em função desta. Esse processo eliminou distorções e possibilitou a análise comparativa entre imagens de diferentes datas e o correto recorte através do limite do município. Após esses procedimentos, as imagens estão prontas para a etapa de classificação digital.

\subsubsection{Classificação Digital de Imagens}

Para os autores Venturieri e Santos (1998) a classificação digital de imagem se apoia em criar um processo de decisão em que se determina uma classe para um grupo de pixels. Desta forma, o software auxilia o usuário na interpretação das imagens orbitais. Nesta situação, se estabelece uma classe a um grupo de pixels, fazendo com que os pixels de igual valor tenham a mesma classificação. Segundo Novo (1992), a classificação supervisionada, que será utilizada nessa pesquisa, desempenha a função de agrupar os padrões de imagens semelhantes em classes de uso da terra, o classificador orienta sua busca de classes a partir de amostras de treinamento feitas anteriormente com as classes de interesse da cena. 
Facco et al.: Geotecnologias para monitoramento florestal no município de Nova Palma...

Coletou-se amostras de pixels para cada classe temática identificada nas imagens, entre elas agricultura, água, campo, floresta, solo exposto e sombra. As classes de uso e cobertura da terra identificadas possuem características distintas, a classe agricultura engloba todas as áreas com presença de cultivos agrícolas incluindo pastagens cultivadas. A classe água é caracterizada pelas drenagens, rios, sangas, represas, açudes e demais corpos d'água. Campos são representados por áreas com presença de gramíneas de diversos tamanhos e espécies, geralmente nativas, e vegetação arbustiva de pequeno porte. As florestas são compostas por vegetação arbórea de médio a grande porte geralmente densa, constituindo normalmente matas galeria e por remanescentes de Mata Atlântica localizados geralmente em encostas e morros. A classe solo exposto representa áreas onde há inexistência de cobertura do solo sendo em sua maioria áreas agrícolas, onde há o preparo para novos cultivos ou a recente remoção de cultivos temporários. Já a classe sombra devido ao ângulo de incidência do sensor e ao relevo acidentado do município em que a sombra de porções mais elevadas da superfície é projetada sobre a superfície descaracterizando a resposta espectral do uso ou cobertura da terra existente naquele local. Nessa etapa de classificação, utilizou-se o algoritmo Maxver (Máxima Verossimilhança), para agrupar pixels que apresentam maior probabilidade de pertencer a uma determinada classe de uso e cobertura da terra. Maxver é o método de classificação supervisionado mais comum e considera a ponderação das distâncias entre médias dos níveis digitais das classes e o pixel, utilizando parâmetros estatísticos, isto é, considerando a distribuição de probabilidade normal para cada classe (INPE, 2006).

A qualidade da classificação digital foi avaliada a partir da matriz de confusão das áreas de treinamento das amostras, aplicando-se a fórmula do coeficiente Kappa, um teste estatístico para análise da confiança da classificação supervisionada. Seu valor é a comparação dos mapeamentos produzidos considerando-se a distribuição de percentagem de pixels classificados correta e incorretamente. Landis e Kock (1977) caracterizam diferentes faixas para os valores Kappa. Assim valores maiores que 0,75 representam excelente concordância. Valores abaixo de 0,40 representam baixa concordância e valores situados entre 0,40 e 0,75 representam concordância mediana.

\subsubsection{Análise espacial}

A análise em LEGAL (Linguagem Espacial para Geoprocessamento Algébrico) são comandos para uso em análise geográfica que está em desenvolvimento no software SPRING. Segundo Barbosa (1997) a linguagem LEGAL proposta por Câmara (1995), tem como finalidade prover um ambiente para análise geográfica, englobando operações de manipulação, consulta espacial e operação de apresentação de resultados de consulta e manipulação. As operações são feitas separadamente das operações de consulta e apresentação. A Linguagem LEGAL foi desenvolvida com base no modelo de dados do sistema SPRING, com o objetivo de permitir a efetivação de análise e simulações de fenômenos reais sobre atributos espaciais e não-espaciais (SILVA, 2003). Neste trabalho, foram gerados mapas temáticos da evolução da cobertura florestal, evidenciando a manutenção florestal, o desmatamento e a regeneração no período de 1985 a 2014. Este procedimento permitiu identificar a dinâmica da floresta, que foi considerada em uma das seguintes três situações: manutenção, regeneração e desmatamento. As áreas de manutenção florestal foram consideradas as que apresentaram classe floresta em ambas as datas analisadas. Áreas de regeneração foram consideradas àquelas que se apresentavam classificadas em outra classe (campos, agricultura, solo e água) e que passaram a ser floresta; as áreas de desmatamento foram àquelas que eram floresta e passaram a ser outra classe de uso. Áreas de sombra foram consideradas sem dados de uso da terra.

\section{Resultados e discussão}

\subsection{Análise do mapeamento multitemporal}

A classificação digital de imagens permitiu quantificar a área das classes de uso e cobertura da terra nos anos de 1985 e 2014, verificando a expansão ou redução de sua ocorrência ao final do período. Representando os resultados de quantificação, foram gerados mapas temáticos das classes

REGET - V. 20, n. 1, jan.- abr. 2016, p.417-426 
Facco et al.: Geotecnologias para monitoramento florestal no município de Nova Palma...

mapeadas Sombra (Fig. 2 e 3), sendo encontrado um coeficiente Kappa de 0,85925 para as amostras da classificação da imagem de1985 e 0,99309 para as amostras da classificação da imagem de 2014) o que demonstrou resultados qualificados como excelentes.

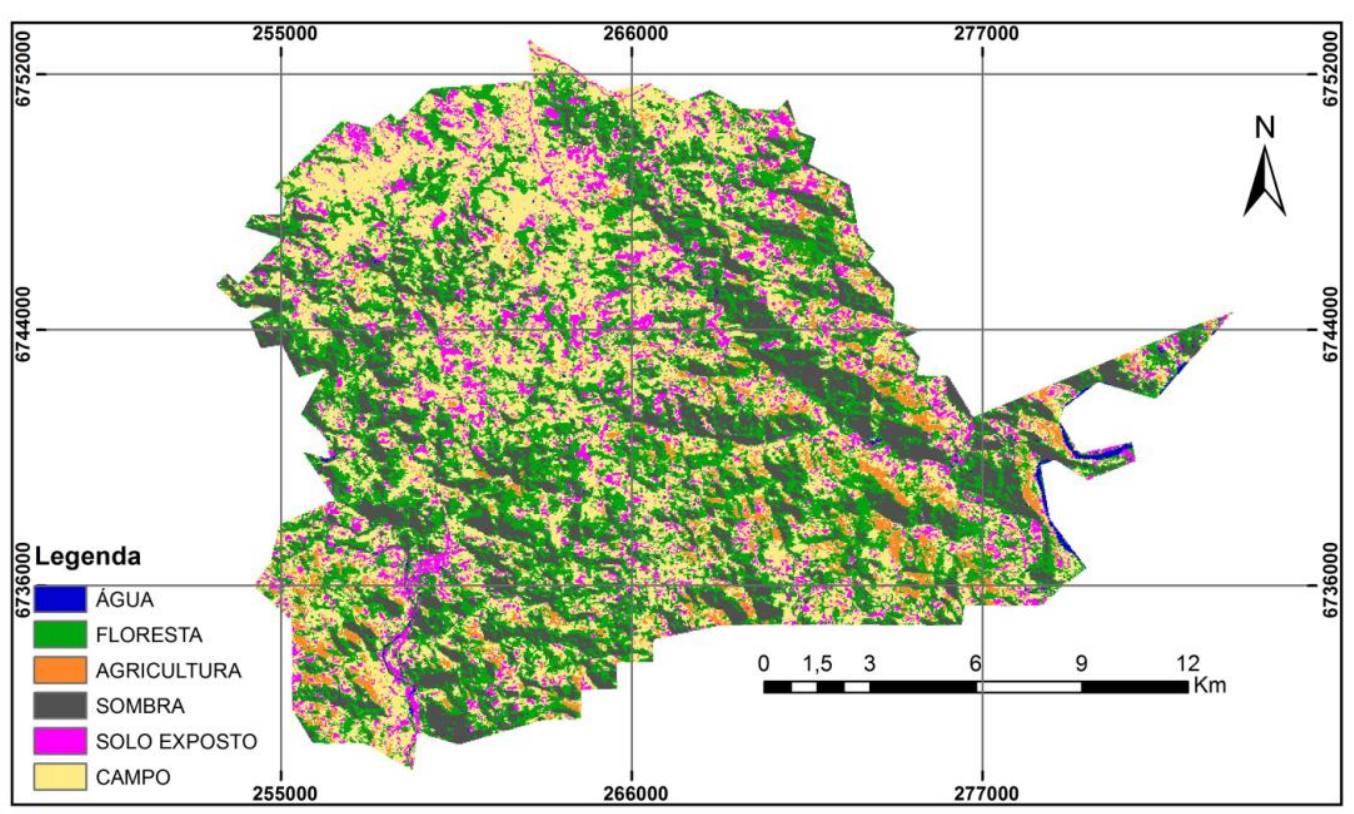

Mapa de uso e cobertura da terra no município de Nova Palma/RS no ano de 1985.

$$
\begin{gathered}
\text { Projeção: UTM, DATUM: Sirgas } 2000 \\
\text { Fuso: } 22 \mathrm{~J} \\
\text { Base Cartográfica: Sensor TM/Landsat } 5 \\
\text { Orbita-Ponto: } 222-080 \\
\text { Fonte: USGS } \\
\text { Elaboração: FACCO, D. S }
\end{gathered}
$$

Figura 2 - Mapa de uso e cobertura da terra no município de Nova Palma/RS no ano de 1985 


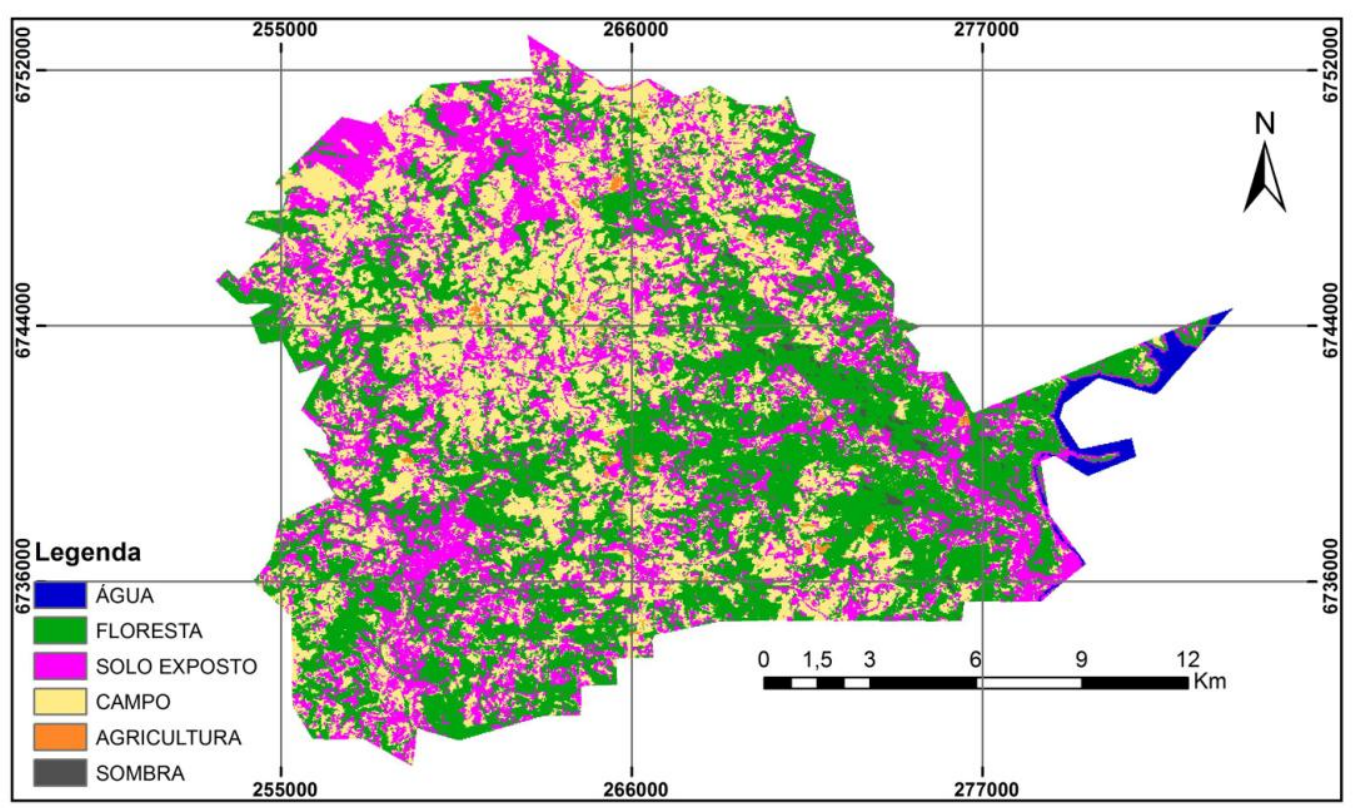

Mapa de uso e cobertura da terra no município de Nova Palma/RS no ano de 2014.

$$
\begin{gathered}
\text { Projeção: UTM, DATUM: Sirgas } 2000 \\
\text { Fuso: } 22 \mathrm{~J} \\
\text { Base Cartográfica: Sensor OLI/Landsat } 8 \\
\text { Órbita-Ponto: } 222-080 \\
\text { Fonte: USGS } \\
\text { Elaboração: FACCO, D. S }
\end{gathered}
$$

Figura 3 - Mapas de uso e cobertura da terra no município de Nova Palma/RS no ano de 2014

Tabela 1 - Áreas $\left(\mathrm{km}^{2}\right)$ quantificadas pela classificação digital das imagens nos anos 1985 e 2014

\begin{tabular}{c|c|c}
\hline \multirow{2}{*}{ Classes } & \multicolumn{2}{|c}{ Áreas classificadas (Km) $\mathbf{~}^{\mathbf{2}}$} \\
\cline { 2 - 3 } & $\mathbf{1 9 8 5}$ & $\mathbf{2 0 1 4}$ \\
\hline Água & 1,65 & 3,91 \\
\hline Agricultura & 16,64 & 2,08 \\
\hline Campo & 130,38 & 111,50 \\
\hline Floresta & 113,32 & 148,58 \\
\hline Solo Exposto & 36,91 & 95,14 \\
\hline Sombra & 63,38 & 1,07 \\
\hline Total & 362,28 & 362,28 \\
\hline
\end{tabular}

Conforme a tabela 1, o mapa do ano de 1985 nos revela o predomínio de campos compreendendo $36 \%$ to total da área, e de florestas com $31,3 \%$. A presença de sombra representou $17,5 \%$ do total da área municipal, interferindo muito nos resultados da classificação digital dessa imagem. A classe solo exposto correspondeu a $10,2 \%$ e a classe agricultura a $4,6 \%$ da totalidade da área. A classe água computou 0,5\% da área, sendo caracterizada basicamente pelo Rio Jacuí.

Em 2014 as classes floresta, campo e solo exposto representaram quase totalidade da área sendo $41 \%, 30,8 \%$ e $26,3 \%$ respectivamente. A classe agricultura computou apenas $0,6 \%$ de área e a classe água apresentou aumento em relação aos períodos anteriores passando a cobrir $1,1 \%$ da área municipal.

A análise da quantificação das áreas de uso e cobertura da terra no período estudado revela o predomínio das áreas de campo e de floresta no interior do município, seguidas por solo exposto vindo confirmar uma das bases do município calcada na produção agropecuária e também seu relevo 
caracterizado pelo rebordo do Planalto Meridional caracterizando o predomínio de florestas nas áreas íngremes e acidentadas.

A classe agricultura apresentou baixos índices, principalmente devido à data de captação das imagens correspondendo ao período do ano em que a terra está sendo preparada para o plantio. A respeito dos pequenos percentuais de área cobertos pela classe água pode-se inferir que é devido ao tamanho não muito significativo de açudes e represas dentro do município caracterizado pela pequena propriedade.

\subsection{Análise da cobertura florestal}

Em uma segunda etapa do trabalho, optou-se por realizar uma análise específica da área floresta, no intuito de identificar processos de manutenção, redução ou expansão. Foi então gerado um mapa de cobertura florestal, a partir dos mapas de uso e cobertura da terra, com base nos cruzamentos destes dados através da programação em linguagem LEGAL. Nestes mapas, concentrou-se apenas na análise da classe de floresta nos anos de 1985 a 2014.

A observação do mapa (Fig. 4) permite identificar que a maior parte das áreas de expansão florestal, ocorridas por reflorestamento de espécies exóticas ou regeneração da vegetação nativa, se concentra na porção leste do município, onde foi implantada a Usina hidrelétrica de Dona Francisca no ano de 2001, o que pode ter ocasionado uma maior preocupação com a preservação dessa área e seus arredores.

Já áreas de redução florestal ou desmatamento ocorreu onde atualmente foi mapeado solo exposto, classe que representa terras que estão sendo preparadas para posteriormente algum tipo de cultivo, visto que a data das imagens é julho e agosto de 2015.

Verifica-se que a manutenção florestal se deu principalmente nas áreas de maior declividade de terreno, nos topos de morros, nas áreas do entorno da rede hidrográfica, indicando a consolidação de Áreas de Preservação Permanente (APP).
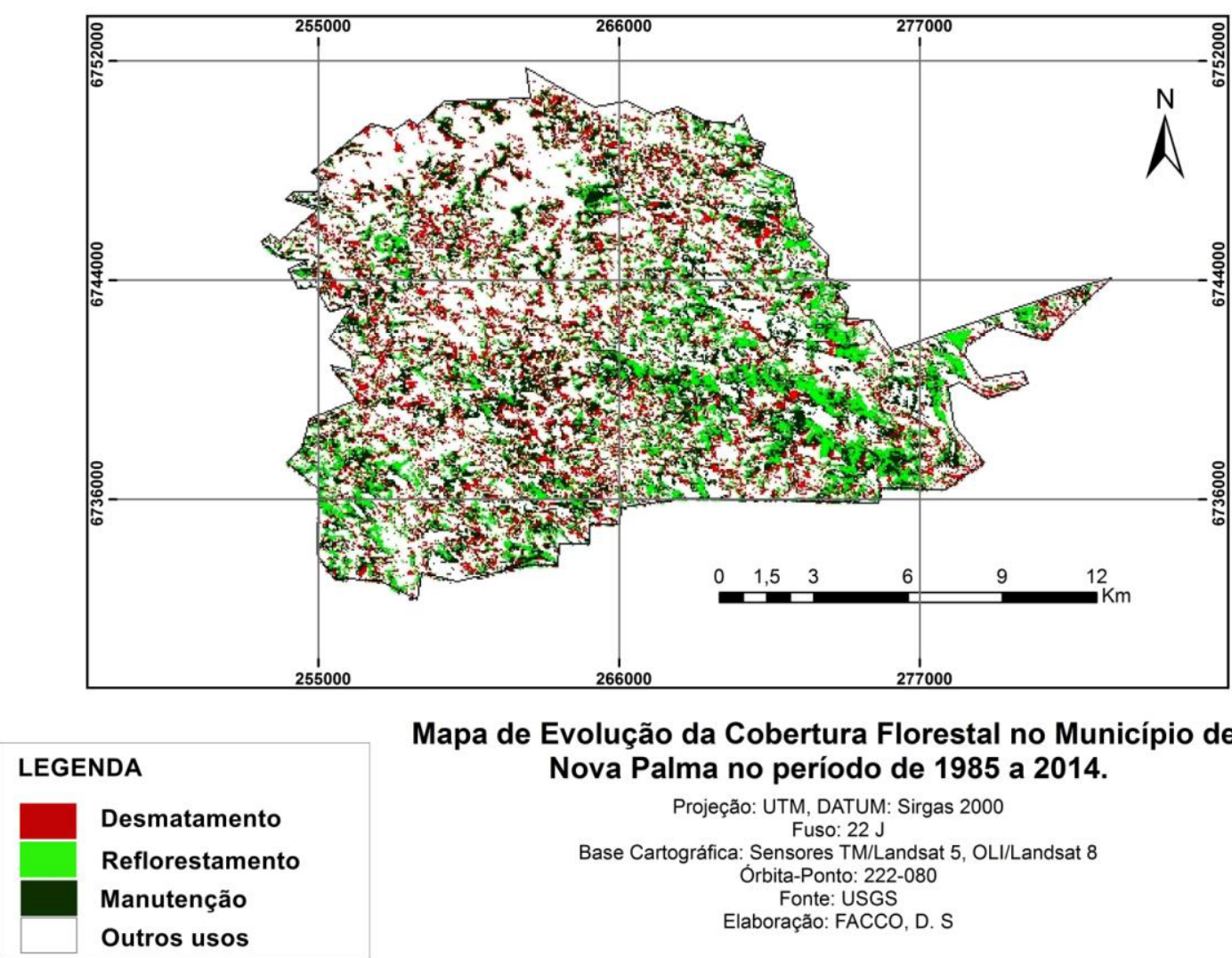

Mapa de Evolução da Cobertura Florestal no Município de Nova Palma no período de 1985 a 2014.

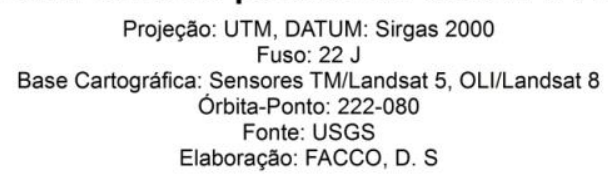

Figura 4 - Mapa de Evolução da Cobertura Florestal no Município de Nova Palma no período de 1985 a 2014. 
Facco et al.: Geotecnologias para monitoramento florestal no município de Nova Palma...

\section{Conclusão}

A utilização conjunta de geotecnologias como o sensoriamento remoto e o geoprocessamento possibilitou a análise integrada das informações mapeadas, evidenciando os processos de manutenção, regeneração florestal e desmatamento, ocorridos durante 29 anos (entre 1985 e 2014). Observou-se que as áreas de maior expansão florestal se concentram na porção leste do município, região onde foi implantada a Usina hidrelétrica de Dona Francisca no ano de 2001; esse empreendimento pode ter provocado uma maior preocupação com a preservação dos recursos naturais em seus arredores. Já ás áreas de ocorrência de desmatamento foram verificadas onde mais recentemente, em 2014, encontrou-se o solo exposto, representando terras que estavam sendo preparadas durante o inverno, para posteriormente receber algum tipo de cultivo agrícola. A manutenção florestal se deu principalmente em locais de maior declividade do terreno, nos topos de morro e nas áreas do entorno da rede hidrográfica, que são consideradas como Áreas de Preservação Permanente (APP).

Espera-se que esses resultados possam subsidiar futuros estudos que o complementem, permitindo a utilização de informações e um melhor conhecimento sobre a dinâmica da paisagem do município de Nova Palma.

\section{Agradecimentos}

A Universidade Federal de Santa Maria (UFSM) e ao Conselho Nacional de Desenvolvimento Científico e Tecnológico (CNPq) pelo apoio ao desenvolvimento deste trabalho. Resultados parciais deste trabalho foram apresentados em forma oral nas Jornadas Argentinas de Geotenologias.

\section{Referências}

Barbosa C. Álgebra de mapas e suas aplicações em sensoriamento remoto e geoprocessamento. [dissertação]. São José dos Campos/SP: Mestrado em Sensoriamento Remoto/ Instituto Nacional de Pesquisas Espaciais; 1997. 161 p.

Carvalho Júnior OA, Guimarães RF, Carvalho APF, Gomes RAT, Melo AF, Silva PA. Processamento e análise de imagens multitemporais para o perímetro de irrigação de Gorutuba/MG. In: Actas XII SIMPÓSIO BRASILEIRO DE SENSORIAMENTO REMOTO [internet]; 2005 abril 16-21; Goiânia, Brasil. 2005 [acesso em 2015 setembro 28]. Disponível em: http://marte.sid.inpe.br/col/ltid.inpe.br/sbsr/2004/12.06.13.32/doc/473.pdf.

Ferrari R. Modelagem Dinâmica do Uso e Cobertura da Terra da Quarta Colônia, RS. [dissertação].Santa Maria/RS: Mestrado em Geomática/ Universidade Federal de Santa Maria; 2008. $138 \mathrm{p}$.

Florenzano, TG. Iniciação em Sensoriamento Remoto. Gráfica. 3st ed. São Paulo: Oficina de textos; 2011.

Instituto Brasileiro de Geografia e Estatítica [internet]. Brasília: Ministério do Planejamento, Censo da população 2010 (BR) [acesso em 2015 junho]. Disponível em: http:// www.ibge.gov.br.

Instituto Nacional de Pesquisas Espaciais. Introdução à Ciência da Geoinformação. [internet]. São José dos Campos; 2001 [acesso em 2015 setembro 27]. Disponível em: http://mtcm12.sid.inpe.br/attachment.cgi/sid.inpe.br/sergio/2004/04.22.07.43/doc/publicacao.pdf. 
Facco et al.: Geotecnologias para monitoramento florestal no município de Nova Palma...

Instituto Nacional de Pesquisas Espaciais, Divisão de processamento de Imagem [internet]. Tutoriais de Geoprocessamento. Classificação de Imagens. São José dos Campos; 2006 [acesso em 2016 janeiro 12]. Disponível em: http://www.dpi.inpe.br/spring/portugues/tutorial/classific.html

Jensen J. Sensoriamento Remoto do Ambiente - Uma Perspectiva em Recursos Terrestres. 2st ed São Paulo: Parêntese; 2009.

Landis RJ, Koch GG. [The measurement of observer agreement for categorical data]. Sociedade Internacional de Biometric, 1977 mar. 159-174. English.

Lucena I, Câmara G, Nascimento AM. Um ambiente de Geração de Programas de Análise Espacial. GIS, 1999. 17 p., Salvador, Brasil.

Moreno JA. Clima do Rio Grande do Sul. Secretaria da Agricultura. Porto Alegre. 1961.

Novo ELM. Sensoriamento Remoto: Princípios e Aplicações. 4st ed. São Paulo: Edgar Blücher. 2008.

Novo ELM. Sensoriamento Remoto: Princípios e Aplicações. 1st ed. São Paulo: Edgar Blücher. 1992.

Rossato PS. O sistema termodinâmico do clima urbano de Nova Palma, RS: Contribuição ao clima urbano de cidades pequenas [dissertação]. Santa Maria/RS Mestrado em Geografia/ Universidade Federal de Santa Maria; 2010. 121 p.

Silva AM, Xavier APC, Medeiros IC, Maranhão KUA, Silva RM. Análise multitemporal e atualização do mapa de uso e ocupação do solo do município de Monteiro/PB. In: Actas XVI SIMPÓSIO BRASILEIRO DE SENSORIAMENTO REMOTO [internet]; 2013 jun 21; Foz do Iguaçu, Brasil. 2013 p. $1548 \quad-1555$. [acesso em 2015 setembro 29] Disponível em http://www.dsr.inpe.br/sbsr2013/files/p1013.pdf.

Silva AB. Sistemas de Informação Geo-referenciadas: conceito e fundamentos. 1st ed. Campinas: Editora da UNICAMP; 2003.

Teixeira ALA, Christofoletti A. Sistemas de Informação Geográfica: Dicionário Ilustrativo. São Paulo: Editora Hucitec Ltda; 1997.

Venturieri A, Santos JR. Técnicas de classificação de imagens para análise da cobertura vegetal. En: ASSAD, E. D. y SANO, E. E. (Ed.). Sistemas de Informações Geográficas: Aplicações na Agricultura. p. 351-371. 2 ed. EMBRAPA, Brasília. 1998. 